\title{
Mit dem Östronspiegel steigt das Prostatakarzinom-Risiko
}

Mit Hochdruck wird versucht, den Ursachen der ProstatakarzinomEntstehung auf die Spur zu kommen. Die Sexualhormone scheinen dabei eine entscheidende Rolle zu spielen: vor allem Östron, wie eine US-amerikanische Studie ergab.

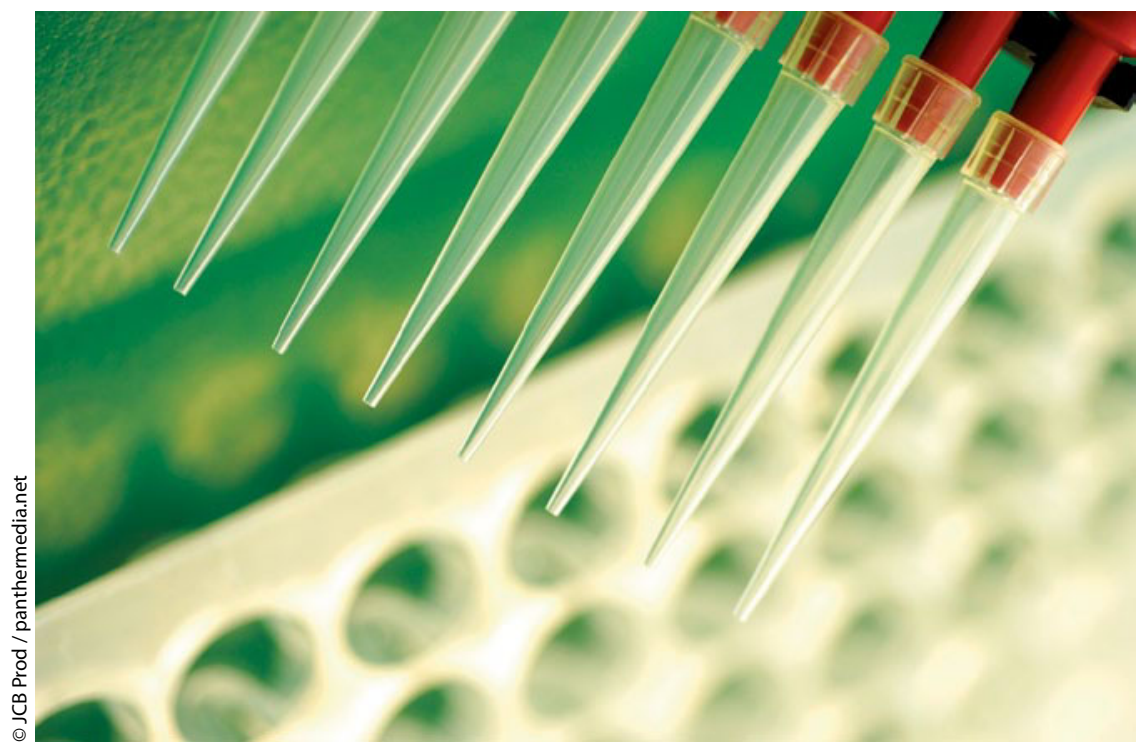

Wissenschaftler fahnden mit Nachdruck nach den Ursachen für die Entstehung von Prostatakrebs. Ein hoher Östronspiegel könnte dabei ein Indikator sein.

I der Antwort auf die Frage, ob und wie die Geschlechtshormone das Prostatakarzinomrisiko beeinflussen, näher zu kommen, analysierten US-amerikanische Forscher in einer Fall-KohortenStudie die Daten aus der aktuell laufenden Osteoporotic Fractures in Men (MrOS)Studie. An der MrOS-Studie nehmen insgesamt 5.995 Männer aus sechs verschiedenen Regionen der USA teil. Alle Probanden sind mindestens 65 Jahre alt.
Nach einer durchschnittlichen Nachbeobachtungszeit von 4,7 Jahren wurden alle Männer, bei denen ein Prostatakarzinom diagnostiziert wurde, sowie eine zufällig zusammengestellte Gruppe aus dem MrOS-Patientenpool für die weitere Analyse ausgewählt. Männer, deren Anamnese zu Beginn der MrOS eine bereits früher diagnostizierte Prostatakrebserkrankung oder eine Androgen- oder Antiandrogentherapie beinhaltete, wurden von der weiteren Untersuchung ausgeschlossen. Übrig blieben 275 Männer mit Prostatakarzinom und 1.652 Männer ohne Prostatakarzinom sowie deren Hormonprofile. Serum-Testosteron, Östradiol, Östron und Sexualhormon-bindendes Globulin wurden zu Studienbeginn gaschromatografisch und massenspektrometisch bestimmt. Der Zusammenhang zwischen der Prostatakrebsinzidenz und jedes der gemessenen Geschlechtshormone wurde mithilfe der Cox-Regression untersucht, bereinigt nach Alter, Rasse, Bildung, Body-MassIndex und Untersuchungsdauer je Person.

Die Probanden der Subkohorte waren durchschnittlich 73 Jahre alt. Bei ihnen waren höhere Östronspiegel signifikant mit einem höheren Prostatakarzinomrisiko assoziiert. Bei Männern, deren Östronspiegel in dem höchsten der vier Quartile lag (> 24,9 pg/dL), war das Krebsrisiko viermal so hoch wie bei Männern mit niedrigeren Werten $(\mathrm{HR}=3,93$, CI: 1,61-9,57). Bei allen anderen Geschlechtshormonen zeigte sich kein $\mathrm{Zu}$ sammenhang.

Fazit: Eine hoher Östronspiegel war eindeutig mit einem höheren Prostatakarzinomrisiko assoziiert. Dennoch bleibt es unklar, ob eine einmalige Serumdiagnostik ausreicht, um das Prostatakarzinomrisiko eines Patienten tatsächlich beurteilen zu können, so die Autoren. $\quad$ dk

Daniels NA et al. Sex Hormones and the Risk of Incident Prostate Cancer. Urology 2010, 76: $1034-40$ 